\title{
Ground Cover Impacts on Sediment and Phosphorus Export from Manured Riparian Pasture
}

\author{
David M. Butler, Dorcas H. Franklin,* Noah N. Ranells, Matthew H. Poore, and James T. Green, Jr.
}

\begin{abstract}
Maintaining pasture ground cover is important in preventing environmental degradation of grasslands and associated riparian areas. The objective of this work was to determine the effect of ground cover on sediment and $P$ export from pastured riparian areas under simulated rainfall events. Plots were established on two sites in the North Carolina Piedmont: a 10\% slope with Appling sandy loam soils (fine, kaolinitic, thermic Typic Kanhapludults) and a $20 \%$ slope with Wedowee sandy loam soils (fine, kaolinitic, thermic Typic Kanhapludults), both with mixed tall fescue (Festuca arundinacea Schreb.)dallisgrass (Paspalum dilatatum Poir.) vegetation. Existing forage stands were modified to represent a range of ground cover levels: 0,45 , 70, and $95 \%$ (bare ground, low, medium, and high cover, respectively), and amended with beef steer (Bos taurus) feces and urine (about $10 \mathrm{~kg}$ $\mathrm{P} \mathrm{ha}{ }^{-1}$ ). Mean runoff volume from bare ground was generally twice that observed from low, medium, and high levels of cover, which were similar. For all rainfall events combined, export of dissolved reactive $P$ was greatest $(P<0.1)$ at bare ground and was reduced $31 \%$ at low cover, which did not differ from medium or high cover. Mean total Kjeldahl P export was greater $(P<0.001)$ from bare ground than from other cover levels. Results indicate that riparian bare areas can contribute substantial sediment $\left(>215 \mathrm{~kg} \mathrm{ha}^{-1}\right)$ and $\mathrm{P}\left(0.7 \mathrm{~kg} \mathrm{P} \mathrm{ha}^{-1}\right)$ to surface waters during heavy rainfall, whereas export may be reduced equally well by low cover $(45 \%)$ as by high cover.
\end{abstract}

$\mathrm{N}$ ONPOINT POLLUTION by losses of agricultural $\mathrm{P}$ has been shown to contribute to eutrophication of surface waters (Carpenter et al., 1998). Eutrophication can lead to algal blooms, reduced dissolved oxygen levels, fish kills, reduced biodiversity, and other negative impacts which may compromise the capacity of surface waters to support beneficial ecosystem functions. Increased sediment loads have been widely reported to reduce populations of benthic organisms and fish, as well as reduce overall primary productivity of aquatic ecosystems (Cooper, 1993).

Grazing cattle can be a source of nutrients and may increase sediment losses from pastures to surface waters in the eastern USA (White et al., 1980; Schepers and Francis, 1982; Byers et al., 2005). However, the impact of grazing livestock on nutrient and sediment export to North Carolina surface waters has not been well quantified. In 2002, it was estimated that more than

D.M. Butler, N.N. Ranells, and J.T. Green, Jr., Department of Crop Science, North Carolina State University, Box 7620, Raleigh, NC 27695; D.H. Franklin, USDA-ARS, J. Phil Campbell Sr. Natural Resource Conservation Center, 1420 Experiment Station Road, Watkinsville, GA 30677; M.H. Poore, Department of Animal Science, North Carolina State University, Box 7621, Raleigh, NC 27695. Received 13 Sept. 2005. *Corresponding author(dfrankln@uga.edu).

Published in J. Environ. Qual. 35:2178-2185 (2006).

Technical Reports: Surface Water Quality

doi:10.2134/jeq2005.0351

(c) ASA, CSSA, SSSA

677 S. Segoe Rd., Madison, WI 53711 USA
705000 ha, or $19 \%$ of North Carolina agricultural land area, was used for grazing (USDA, 2002), which makes determining the impact of grazing on water quality critically important. Specifically, the importance of riparian area management to quality of surface waters underscores the need for scientific investigation of environmental impacts when riparian areas are grazed.

Riparian areas unsuitable for row crop production due to topography and seasonal flooding are sometimes grazed. These riparian areas can have relatively high forage productivity because of favorable moisture conditions, even during drier periods. However, poor grazing management can lead to reduced stand density and forage ground cover (Alderfer and Robinson, 1947; Bates et al., 1996; McKenzie, 1997). Poor stands can negatively influence infiltration, runoff, erosion, and sediment deposition (McGinty et al., 1979; Self-Davis et al., 2003) and limit the ecosystem services provided by the riparian area. While there are data relating to runoff volume, sediment, and nutrient export from grasslands in the Southeast, there are few data that report the level of ground cover necessary to protect water quality when livestock graze in or near riparian areas.

Several studies in diverse environments have suggested threshold levels of 70 to $75 \%$ ground cover, below which significant runoff and sediment loss can occur (Costin, 1980; Lang, 1979; Mwendera and Saleem, 1997). Lang (1979) indicated that when ground cover was $<75 \%$, as estimated by the point or area quadrat method, bare areas began to connect with each other which allowed for faster flow of runoff and less time for infiltration. Also using the quadrat method, Costin (1980) reported that ground cover $<70 \%$ resulted in greater mean soil loss and runoff rate than ground cover $>70 \%$.

Slightly different results were reported by Dadkhah and Gifford (1980) in a Utah study on infiltration rate and sediment production. Cover was established by uprooting vegetation in randomly selected squares of a grid. The researchers reported no difference in infiltration rate on plots with either 50 or $80 \%$ ground cover. The researchers suggested that ground cover levels of $50 \%$ or greater may be sufficient for adequate watershed protection.

In Arkansas, Self-Davis et al. (2003) examined the effects of forage canopy cover on runoff volume from plots on a $5 \%$ slope. Though there was a trend toward greater runoff volume with forage clipping and resulting reduced canopy cover, height of forage did not significantly impact runoff volume from any forage species compared to unclipped plots. Edwards et al. (2000b) ex-

Abbreviations: DRP, dissolved reactive phosphorus; TKP, total Kjeldahl phosphorus; TP, total phosphorus; TSS, total suspended sediments; WEP, water extractable phosphorus. 
amined relationships between tall fescue clipping height and nutrient export from applied feces and urine and reported few total $\mathrm{P}$ (TP) concentration differences in runoff between treatments of unclipped forages or forages clipped to heights of $2.5,10$, or $20 \mathrm{~cm}$. As expected, the lowest TP concentrations in runoff were observed from plots that did not receive feces and urine. Low TP concentrations were also reported during rainfall events $21 \mathrm{~d}$ after feces and urine application, rather than rainfall events immediately after feces and urine application.

Our objectives were to determine fundamental relationships between ground cover in riparian pastures and the export of sediment and $\mathrm{P}$ under simulated grazing conditions (application of beef steer feces and urine and simulated hoof compaction) using simulated rainfall. Specifically, this paper examines the impact of bare ground and low, medium, and high ground cover levels on runoff volume and export of total suspended sediments (TSS), dissolved reactive P (DRP), and total Kjeldahl P (TKP) from two sites of 10 and $20 \%$ slope in riparian pasture plots.

\section{MATERIALS AND METHODS Site Description}

In February 2003, research plots were established on existing mixed tall fescue-dallisgrass vegetation that was managed as pasture for $20 \mathrm{yr}$ at North Carolina State University's Lake Wheeler Road Field Laboratory, Raleigh, NC ( $35^{\circ} 43^{\prime} \mathrm{N}$; $78^{\circ} 41^{\prime} \mathrm{W}$; elevation is $100 \mathrm{~m}$ ). Randomized complete block experiments were established on two slopes (about 10 and about $20 \%$ ), 5 to $10 \mathrm{~m}$ landward from a stream. Soils were Appling sandy loam on the $10 \%$ slope site and Wedowee sandy loam on the $20 \%$ slope site. Soil cores were examined before plot establishment to ensure consistency of soils within block and within slope.

Experimental plots were 0.75 by $2.0 \mathrm{~m}$ and delineated with $23-\mathrm{cm}$ high flashing inserted to a soil depth of $18 \mathrm{~cm}$ to isolate the surface hydrology of the plots. A runoff collection gutter was placed at the down-slope edge of each plot.

\section{Cover Treatments}

Upon initiation of this study, four ground cover treatments were established with four replications of each treatment, for a total of 16 plots on each site. Ground cover levels were created by establishing $100 \%$ bare soil area with $0 \%$ ground cover, $55 \%$ bare soil area with $45 \%$ ground cover, $30 \%$ bare soil area with $70 \%$ ground cover, and not altering full (95\%) vegetative cover plots. Bare soil areas were created using a 5 by $10 \mathrm{~cm}$ rectangular grid and a small hand flame to quickly heat and kill statistically random blocks of vegetative cover. The random blocks created a pattern of varying sizes of bare soil areas as selected blocks connected with each other. After using the flame, herbage residue was raked from the plots. The plots were given several weeks to recover and any remaining residue was removed during subsequent natural rainfall events. Small rectangles of black plastic were placed on the plots in the same random grid pattern to maintain desired ground cover between rain events once the treatments of feces and urine were applied to the plots. Plastic was removed before simulated rain events.

The $0 \%$ ground cover treatment was established in each replication to simulate a compacted, cattle heavy use or 'lounging' area. Simulated lounging treatments were established by using black plastic to cover the whole plot and solarize all vegetation. A steel compaction device with an impact surface area of $100 \mathrm{~cm}^{2}$ was used to simulate cattle hoof compaction over the entire $0 \%$ cover plot, using methods described by Clary (1995). Simulated lounging plots were compacted before the first simulated rain event in the spring and again before the first fall rain event.

To standardize canopy height at each rain event, plots were harvested to a $10-\mathrm{cm}$ stubble height before each rainfall simulation, as well as in July 2003 for plot maintenance. The forage samples from each harvest were weighed and dried $\left(65^{\circ} \mathrm{C}\right)$, then analyzed by the North Carolina Department of Agriculture and Consumer Services (NCDA\&CS) Agronomic Division for TP by the photometric method described in AOAC method 965.17 (Cunniff, 1995). Percent canopy cover was determined using the line transect method (Laflen et al., 1981) with 40 points after the vegetation was harvested to $10 \mathrm{~cm}$ and just before the rainfall simulations.

\section{Rainfall Simulations}

Before each simulated rainfall, three soil cores of 0 - to $5-\mathrm{cm}$ depth $(1.75-\mathrm{cm}$ i.d.) were obtained from each plot. The cores were combined by plot to form a composite sample, which was divided into two subsamples for each plot. One sample was airdried and ground, while the second was placed in a soil moisture can and dried at $105^{\circ} \mathrm{C}$ for $24 \mathrm{~h}$ to determine gravimetric soil moisture content. Mehlich-3 soil $\mathrm{P}$ was determined on the dried and ground sample (Mehlich, 1984).

Three rainfall simulators (Tlaloc 3000, Joern's, West Lafayette, IN) were used to simulate rainfall at an intensity of $70 \mathrm{~mm} \mathrm{~h}^{-1}$ for a 1-h duration. This is just above a 10-yr, 1-h rain event of about $65 \mathrm{~mm} \mathrm{~h}^{-1}$ for Raleigh, NC, whereas a 25-yr, 1-h rain event for Raleigh is about $85 \mathrm{~mm} \mathrm{~h}^{-1}$ (Hershfield, 1961). Simulators were randomly assigned to blocks at each rain event, and the same simulator was used on all plots within a block. Each simulator rained on two plots simultaneously. In April 2003, an initial rainfall simulation was conducted to determine baseline runoff conditions from each plot before application of feces and urine. Deionized water was used as source water for the rainfall simulators. Great care was taken to ensure equal volume and distribution of rainfall from each simulator each time used. Simulators were calibrated by measuring volume and distribution of rain and adjusting the pressure valve at each simulator accordingly before moving simulators onto plots. Rain gauges were placed in plots to verify rainfall rate for each rain event.

Time was recorded as runoff began to drip from the gutter and the initial $125 \mathrm{~mL}$ of runoff was collected. When steady flow began, time was again recorded and a timer started so that runoff could be sampled beginning at 5, 10, 15, 20, 25, and 30 min after initiation of steady runoff flow. At each sampling time interval, $500 \mathrm{~mL}$ of runoff was obtained. Runoff between samplings was collected into large containers and weighed every 5 min after the initiation of steady runoff state until $30 \mathrm{~min}$ of runoff had occurred from each plot. The same methods of rainfall application and runoff collection were used for all rainfall simulations.

\section{Feces and Urine Application}

Feces and urine were applied in late May to plots immediately before rainfall simulations at a rate that approximated $10 \%$ of the average daily output for mature cattle (Kohn et al., 2005). This equated to a 2.4-kg deposit of moist feces (at $850 \mathrm{~g}$ $\mathrm{H}_{2} \mathrm{O} \mathrm{kg}{ }^{-1}$ wet manure) applied on a $550-\mathrm{cm}^{2}$ area and a $1-\mathrm{L}$ 
urine deposit applied over an equal area. The center of the fecal deposit was placed $30.5 \mathrm{~cm}$ from the top of the plot and centered between the plot sides. The 1-L urine deposit was placed directly adjacent and down slope of the fecal deposit. Assuming even distribution of feces and urine within a pasture, the two applications to each plot are representative of a stocking rate of about 4 cows ha-1 $\mathrm{yr}^{-1}$. Relatively low agronomic rates of $\mathrm{P}\left(<10 \mathrm{~kg} \mathrm{P} \mathrm{ha}^{-1}\right)$ were applied to plots at each application of feces and urine (Table 1). The amount of WEP in manures has been reported to be highly correlated to runoff P (Kleinman et al., 2002a) and in this study, WEP applied to plots as feces averaged $2.3 \mathrm{~kg} \mathrm{P}^{-1}$.

The feces and urine were collected from four beef steers fed switchgrass (Panicum virgatum L.) and gamagrass [Tripsacum dactyloides (L.) L.] hay as part of an unrelated study. Feces were mixed and formed into $2.4-\mathrm{kg}$ portions (about $0.33 \mathrm{~kg}$ dry matter) 25 by $14 \mathrm{~cm}$ wide and $6 \mathrm{~cm}$ thick before being frozen until thawed for plot application. Urine was collected in buckets placed under the steers while in metabolism crates. All collected urine was mixed, adjusted to a $\mathrm{pH}$ level of 6 with $\mathrm{HCl}$ to prevent precipitation of solids and $\mathrm{N}$ losses to ammonia $\left(\mathrm{NH}_{3}\right)$, and then frozen until thawed for plot application. Feces and urine were analyzed by the NCDA\&CS Agronomic Division for TP by inductively coupled plasma-atomic emission spectrometry (ICP-AES) as described in USEPA Method 200.7 (USEPA, 1992). Water extractable P (WEP) was determined by methods described by Kleinman et al. (2002b). Fresh manure samples (1-g dry weight equivalent) were shaken with $200 \mathrm{~mL}$ of deionized water for $1 \mathrm{~h}$, centrifuged, filtered through $0.45-\mu \mathrm{m}$ cellulose nitrate membranes, and analyzed for dissolved reactive $\mathrm{P}$ (DRP) by the molybdate blue method (Murphy and Riley, 1962).

Following rainfall simulations in May 2003, plots were covered during natural rainfall events to prevent runoff until the final forage harvest of the experiment in November 2003. Rainfall simulations were again conducted 9 to 11 June 2003 to determine runoff constituents from plots, but without additional application of feces and urine. Plots were again treated with feces and urine before rainfall simulations on 9 to 11 Sept. 2003, which were followed by rainfall simulations 6 to 8 Oct. 2003 without additional plot treatment with feces and urine. Feces and urine application in September was on the same location on the plot, but the recognizable fecal material remaining from the spring was manually removed from the plot, weighed, and a 30-g sample removed for TP determination. The remaining fecal mass was manually broken up into about 25 pieces of similar size and distributed in the $2500-\mathrm{cm}^{2}$ area surrounding the original fecal deposit immediately before the new application of feces and urine in September.

\section{Sample Collection and Analysis}

Runoff sample vials were placed in ice and in the dark until transported to the lab. Vacuum filtration $(0.45 \mu \mathrm{m})$ of $100 \mathrm{~mL}$ of runoff sample was used to determine concentration of TSS. Filters were dried at $105^{\circ} \mathrm{C}$ for $24 \mathrm{~h}$ and weighed before and

Table 1. Phosphorus application rate in cattle feces and urine.

\begin{tabular}{lccc}
\hline Rain event & Manure component & Total P & WEP $\dagger$ \\
\cline { 2 - 4 } May 2003 & & \multicolumn{2}{c}{ kg P ha $^{-1}$} \\
& feces & 7.7 & 2.1 \\
September 2003 & urine & 1.1 & N/A \\
Total & feces & 5.6 & 2.4 \\
& urine & 0.8 & N/A \\
& feces & 13.3 & 4.5 \\
\hline
\end{tabular}

$\dagger$ Water extractable P. after filtration. Dissolved reactive $\mathrm{P}$ was determined by analyzing the filtered sample by the molybdate blue method (Murphy and Riley, 1962). Total Kjeldahl P was determined similarly following Kjeldahl digestion of an unfiltered sample according to USEPA Method 365.4 (USEPA, 1979).

Runoff samples collected at 5-min intervals represented point estimates of concentrations and were plotted vs. cumulative runoff volume. The points were joined with straight lines and the area under the plot was integrated according to the trapezoid rule using the PROC EXPAND procedure (SAS Institute, 1994). This method determined the cumulative mass of sediment and nutrients lost at each collection time; the main focus here being sediment and $\mathrm{P}$ export during $30 \mathrm{~min}$ of runoff.

The effect of cover, site (a combination of slope and soil differences), and month of rain event to runoff volume, TSS, DRP, and TKP mass export and concentrations was determined by using the PROC GLM procedure (SAS Institute, 1994). Means were separated using Fisher's least significant difference. Unless otherwise noted, differences were considered to be significant at $P<0.05$.

\section{RESULTS AND DISCUSSION Cover}

Target ground cover levels of $0,45,70$, and $95 \%$ were established at the soil surface. As canopy cover measurements often differed from the established level of ground cover, $45 \%$ ground cover will be considered as low cover, $70 \%$ ground cover will be considered as medium cover, and $95 \%$ ground cover will be considered as high cover, with the $0 \%$, compacted treatment referred to as bare ground to facilitate discussion of ground cover treatments. Canopy cover (note: not basal cover) varied across the five rain events (Table 2). Mean canopy cover at low cover ranged from $63 \%$ in April to $78 \%$ in October, canopy cover at medium cover ranged from $76 \%$ in April to $83 \%$ in October, and canopy cover at high cover ranged from $98 \%$ in April to $83 \%$ in October.

Mean canopy cover differed at each level of established ground cover for every rainfall event, except during October. In October, no statistical difference in mean canopy cover was observed between low, medium, and high ground cover levels. As the season progressed, thicker forage growth in grid rectangles that were selected to include live forage likely increased canopy cover values of the low and medium cover levels through some spreading into adjacent bare grid rectangles. This is important to note, as this shielding effect could also shield soil in adjacent blank grid rectangles from raindrop impact.

Table 2. Mean measured canopy cover at each cover level, averaged across sites.

\begin{tabular}{lccccc}
\hline & \multicolumn{5}{c}{ Rain event } \\
\cline { 2 - 6 } Cover & Base & May & June & Sept. & Oct. \\
\cline { 2 - 6 } & & \multicolumn{5}{c}{ canopy cover, \% } \\
Bare & $\mathbf{0 a} \dagger$ & $\mathbf{0 a}$ & $\mathbf{0 a}$ & $\mathbf{0 a}$ & $\mathbf{0 a}$ \\
Low & $\mathbf{6 3 b}$ & $\mathbf{6 5 b}$ & $\mathbf{7 8 b}$ & $\mathbf{7 5 b}$ & $\mathbf{7 8 b}$ \\
Med & $\mathbf{7 6 c}$ & $\mathbf{7 8 c}$ & $\mathbf{8 3 c}$ & $\mathbf{8 0 c}$ & $\mathbf{8 0 b}$ \\
High & $\mathbf{9 4 d}$ & $\mathbf{9 5 d}$ & $\mathbf{9 8 d}$ & $\mathbf{9 2 d}$ & $\mathbf{8 3 b}$ \\
\hline
\end{tabular}

$\dagger$ Means in the same column followed by the same letter are not significantly different $(P>0.05)$. 


\section{Rainfall Rate and Distribution}

At simulated rain events, a rainfall rate of $70 \mathrm{~mm} \mathrm{~h}^{-1}$ was the output target for each rainfall simulator. However, rainfall rate determined from rain gauges at the plots recorded a higher mean rainfall rate of $102 \mathrm{~mm} \mathrm{~h}^{-1}$ with a standard deviation of $15 \mathrm{~mm} \mathrm{~h}^{-1}$. Mean rainfall rate and rainfall rate recorded adjacent to feces and urine deposits were included as covariates in initial statistical models to account for any variation, but were not significantly related to runoff volume or cumulative export of TSS, DRP, or TKP during 30 min of runoff and so were not included in statistical models. As the same simulator was used on all plots within a block, the block effect in the statistical model helps account for differences among the rainfall simulators.

\section{Runoff Volume}

Cumulative runoff volume for $30 \mathrm{~min}$ of runoff was significantly related to cover $(P<0.001)$ and month of rain event $(P<0.05)$, but not to site (Table 3$)$. A strong interaction between cover and month of rain event was also evident $(P<0.001)$. Therefore, in addition to examining mean runoff volumes from the five rain events, volume means by level of cover were also examined at each rain event, averaged over both sites.

Total runoff volume collected during $30 \mathrm{~min}$ of runoff did not differ between low, medium, and high cover for any rainfall simulation event (Fig. 1). However, the mean volume of runoff from all rain events was greater at low cover than at medium and high cover levels, suggesting that $45 \%$ basal cover or about $70 \%$ canopy cover is less effective than greater cover levels at reducing surface runoff. The bare ground treatment produced greater runoff than all other cover levels in every month except June, when all cover levels produced similar runoff volumes. Cumulative volumes of runoff calculated every 5 min displayed similar patterns of differences between cover treatments as did total runoff volume

Table 3. ANOVA: Cumulative total runoff parameters during $30 \mathrm{~min}$ of runoff.

\begin{tabular}{|c|c|c|c|c|c|}
\hline Source & DF & Volume & TSS $\dagger$ & DRP & TKP \\
\hline & & & & & \\
\hline \multicolumn{5}{|c|}{ Hypothesis tests } & $* * *$ \\
\hline Site & 1 & NS & ** & NS & NS \\
\hline Block (site) & 6 & & NS & $* * *$ & \\
\hline Cover & 3 & $* * *$ & $* * *$ & $\S$ & $* * *$ \\
\hline Cover $\times$ site & 3 & ** & **** & $\S$ & $* * *$ \\
\hline Cover × block (site) & 18 & $* * *$ & NS & $* * *$ & $\S$ \\
\hline Rain event & 4 & $*$ & $*$ & $* *$ & $* *$ \\
\hline Cover $\times$ event & 12 & $* * *$ & $* * *$ & $* * *$ & $* * *$ \\
\hline Site $\times$ event & 4 & $\S$ & NS & $* * *$ & $\S$ \\
\hline Block (site) $\times$ event & 24 & * & NS & $* * *$ & NS \\
\hline Cover $\times$ event $\times$ site & 12 & NS & NS & NS & NS \\
\hline Residual & 72 & & & & \\
\hline Total & 159 & & & & \\
\hline \multicolumn{6}{|c|}{$\begin{array}{l}* \boldsymbol{P}<\mathbf{0 . 0 5} . \\
* * \boldsymbol{P}<\mathbf{0 . 0 1} . \\
* * * \boldsymbol{P}<\mathbf{0 . 0 0 1} . \\
\dagger \text { TSS }=\text { total suspended sediments, DRP }=\text { dissoved reactive phosphorus, } \\
\text { TKP }=\text { total Kjeldahl phosphorus. } \\
+\mathbf{N S}=\text { not significant. } \\
\S \boldsymbol{P}<\mathbf{0 . 1} .\end{array}$} \\
\hline
\end{tabular}

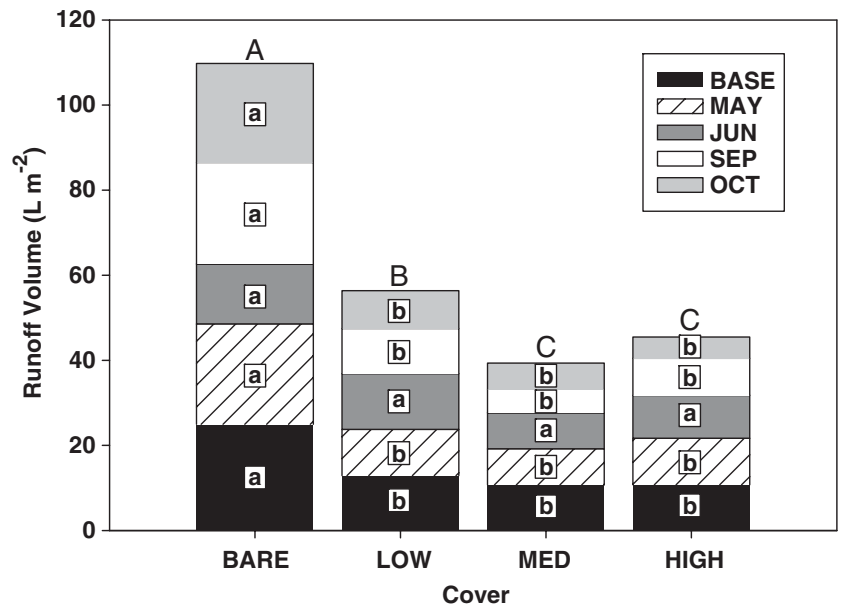

Fig. 1. Mean volume of $30 \mathrm{~min}$ of runoff as affected by cover, averaged across sites (means within the same rain event indicated by the same letter are not significantly different; capital letters indicate differences among the means of all rain events, $P>0.05$ ).

(data not shown). It was expected that bare ground plots would produce the greatest volume of runoff, but it was somewhat unexpected that there were no differences between plots at low, medium, and high cover except for the average of all rain events. Perhaps due to the inherent variability of runoff in this type of study, more observations were necessary to obtain statistical differences. Several researchers have reported a 70 to $75 \%$ range of cover below which a greater volume of runoff is observed (Costin, 1980; Lang, 1979; Mwendera and Saleem, 1997). This was similar to the canopy cover value of the low cover treatment in this study, which was estimated using similar methods. The established low ground cover of $45 \%$ was also similar to the about $50 \%$ threshold level of cover suggested by Dadkhah and Gifford (1980), which was similarly established at the soil surface by removing selected plants from a grid.

There was also an indication of a seasonal effect on runoff volume, with less volume from fall rain events. However, replication of this experiment in subsequent years would help verify the seasonal response indicated during this study and possibly suggest seasonal grazing management for sensitive riparian areas that would minimize environmental contamination.

\section{Total Suspended Sediments}

Cumulative TSS export during $30 \mathrm{~min}$ of runoff was significantly affected by cover $(P<0.001)$, site $(P<$ $0.01)$, and rain event $(P<0.05)$ (Table 3$)$. In addition, there were significant interactions between cover and site $(P<0.001)$ and between cover and rain event $(P<$ $0.001)$, but not between site and rain event.

Due to interactions, mean TSS export was examined at each level of cover on each site (Table 4). From bare ground and low cover treatments, mean cumulative TSS export during $30 \mathrm{~min}$ of runoff on the site of $20 \%$ slope was 2.5 -fold greater than export on the $10 \%$ slope site. This was expected as other researchers have reported greater soil loss (Mwendera and Saleem, 1997) and reduced trapping of sediment (Jin and Romkens, 2001) 
Table 4. Mean cumulative total suspended sediment (TSS) export during $30 \mathrm{~min}$ of runoff.

\begin{tabular}{|c|c|c|c|c|c|}
\hline \multicolumn{2}{|l|}{ Site } & \multicolumn{4}{|c|}{ Cover } \\
\hline \multirow[t]{2}{*}{ Slope } & Soil & Bare & Low & Medium & High \\
\hline & & \multicolumn{4}{|c|}{ TSS export, $\mathrm{kg} \mathrm{ha}^{-1}$} \\
\hline $10 \%$ slope & $\begin{array}{l}\text { Appling sandy } \\
\text { loam }\end{array}$ & $215 a \dagger$ & $10.5 \mathrm{a}$ & $5.88 \mathrm{a}$ & $4.68 a$ \\
\hline $20 \%$ slope & $\begin{array}{l}\text { Wedowee sandy } \\
\text { loam }\end{array}$ & $562 \mathrm{~b}$ & 30.0b & 7.11a & 8.73a \\
\hline
\end{tabular}

$\dagger$ Means within columns followed by the same letter are not significantly different $(P>0.05)$.

with increased slope. Since actual canopy cover values were somewhat higher than established ground cover levels in this study, results were similar to those of Mwendera and Saleem (1997) who suggested critical values for preventing soil losses in Ethiopia at $70 \%$ canopy cover at 0 to $4 \%$ slope and $85 \%$ cover for pasture with 4 to $8 \%$ slope. However, at medium and high cover, there were no significant differences in mean TSS export between the two sites in our study. This indicates that the medium cover level (about $80 \%$ canopy cover) protected sites on slopes of 20 and $10 \%$ equally well. In contrast, increased TSS export was observed from low cover (about $70 \%$ canopy cover) plots at the $20 \%$ slope site. Because the soils on the two sites differed slightly, the difference in TSS export cannot be solely attributed to slope, but this provides a good starting point for further research. Replication on other sites and soil types will be necessary to more closely examine the impact of slope to TSS export in pastured riparian areas. This is especially important due to the wide variations of slope typical to Piedmont riparian areas.

As expected, due to the exposed soil surface in bare ground treatments, there was greater mean cumulative TSS export from the bare ground treatment than all other cover levels (data not shown). However, the magnitude of the difference was less during rain events with lower runoff volume. At all rain events, plots with cover levels established at $45 \%$ or greater had relatively low mean TSS export $\left(<35 \mathrm{~kg} \mathrm{ha}^{-1}\right)$.

\section{Soil Phosphorus}

Soil $\mathrm{P}$ has been shown to be an important determinant of the amount of dissolved $\mathrm{P}$ in runoff (Pote et al., 1996). In this study, Mehlich-3 soil $\mathrm{P}$ generally did not vary significantly across each cover level and rain event, averaging 50 to $60 \mathrm{mg} \mathrm{P} \mathrm{kg}^{-1}$ (Table 5). Soil $\mathrm{P}$ was included as a covariate in statistical analysis of DRP and

Table 5. Mean soil $P$ as affected by cover, averaged across sites.

\begin{tabular}{lccccc}
\hline & \multicolumn{5}{c}{ Rain event } \\
\cline { 2 - 6 } Cover & Base & May & June & Sept. & Oct. \\
\hline & \multicolumn{5}{c}{ Mehlich-3 soil P, mg P kg } \\
Bare & $\mathbf{5 0 . 7}$ & $\mathbf{5 3 . 3}$ & $\mathbf{5 9 . 4}$ & $\mathbf{5 6 . 4}$ & $\mathbf{5 8 . 1 a}$ \\
Low & $\mathbf{5 0 . 5}$ & $\mathbf{5 7 . 4}$ & $\mathbf{5 7 . 0}$ & $\mathbf{4 9 . 4}$ & $\mathbf{5 0 . 5 a b}$ \\
Medium & $\mathbf{5 3 . 0}$ & $\mathbf{5 6 . 2}$ & $\mathbf{5 9 . 2}$ & $\mathbf{5 4 . 7}$ & $\mathbf{4 9 . 2 b}$ \\
High & $\mathbf{5 0 . 7}$ & $\mathbf{4 7 . 2}$ & $\mathbf{5 5 . 2}$ & $\mathbf{4 7 . 4}$ & $\mathbf{4 7 . 8 b}$ \\
\hline
\end{tabular}

$\dagger$ Means in the same column followed by the same letter are not significantly different $(P>0.05)$.
TKP export during 30 min of runoff, but was not found to be significantly related to either runoff constituent. However, one noticeable trend in the data was the significant buildup of $\mathrm{P}$ in the soil on the bare ground treatment at the end of the study compared to plots at medium and high cover. This was to be expected as there was no vegetation to use applied $P$.

\section{Dissolved Reactive Phosphorus}

Export of DRP was generally less related than other runoff constituents to cover, rain event, and site. Of main effects, rain event had the greatest impact $(P<0.01)$ on cumulative DRP export, cover was also significantly related $(P<0.1)$, but site was not related to DRP export during 30 min of runoff (Table 3 ). There was also a highly significant interaction between cover and rain event $(P<0.001)$. Concentration of DRP in runoff was also examined, and while rain event was highly significant $(P<0.001)$, site and cover were rarely significant at any time of runoff collection (data not shown).

Due to interaction, cumulative DRP export was examined by rain event within each level of cover and averaged across sites (Fig. 2). Mean DRP export from vegetated plots exhibited a similar relationship among rain events; at low, medium, and high cover, mean DRP export was generally greatest during the September rain event and least during the baseline rain event in April. Low export during the baseline rain event was expected, as there was no application of feces or urine to plots. High export during the September event was also expected due to application of feces and urine at that rain event and possibly due to disturbing the remaining fecal deposit from May during the September application. However, DRP export in May did not respond as expected to feces and urine application. There was no greater DRP export in May than that of the baseline event at any level of cover. Export of DRP in May also did not differ from export during June, a rain event which did not include additional feces and urine appli-

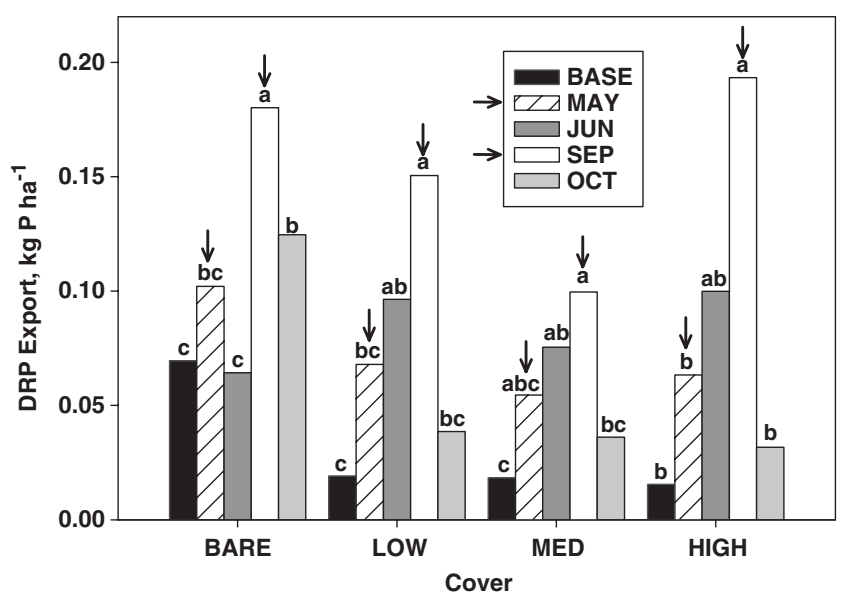

Fig. 2. Mean cumulative dissolved reactive phosphorus (DRP) export during $30 \mathrm{~min}$ of runoff as affected by rain event, averaged across sites (means within the same cover level indicated by the same letter are not significantly different, $P>0.05$ ). The down arrow indicates application of cattle feces and urine. 
cation. Mean DRP export in May and June was rather evenly distributed between the two events, whereas in the fall, there was a large export of DRP in September and a much smaller export in October at each level of vegetative cover. At medium cover, DRP export in September was 2.5-fold greater than in October, and at high cover the export in September was sixfold greater.

The pattern of reduced DRP export in months following application of feces and urine is similar to results reported by Franklin et al. (2006), who reported on DRP losses from applied poultry litter. Export of DRP from plots with rainfall applied 1 mo after litter application was reduced to $27 \%$ of the export observed when rain was applied to plots immediately after litter application. Working with applied cattle feces and urine, Edwards et al. (2000b) reported a similar relationship in DRP concentrations in runoff for rainfall simulations which follow the initial rainfall simulation after application of feces and urine. When the second rainfall event was applied (after manure application and one rainfall event), DRP concentration in runoff decreased about $0.1 \mathrm{mg}$ $\mathrm{L}^{-1}$ in July, and about $0.3 \mathrm{mg} \mathrm{L}^{-1}$ again in August just as was the case in this study for the September and October rainfall events. Similarly, Sauer et al. (1999) reported that soluble reactive $\mathrm{P}$ (SRP) export from applied dairy feces and urine was reduced when rain was applied $14 \mathrm{~d}$ after feces and urine application to $31 \%$ of the export observed when rain was applied $1 \mathrm{~d}$ after feces and urine application.

In this study, cumulative DRP export during $30 \mathrm{~min}$ of runoff (averaged across sites) was also examined by cover level at each rain event, as well as for all rain events combined (Fig. 3). At the baseline event and in October, DRP export from the bare ground treatment was greater than that from low, medium, or high cover levels, which did not differ. In May, there was no difference between DRP export at bare ground and low cover and in June, no differences were observed at any level of cover. In September, DRP export was lower at

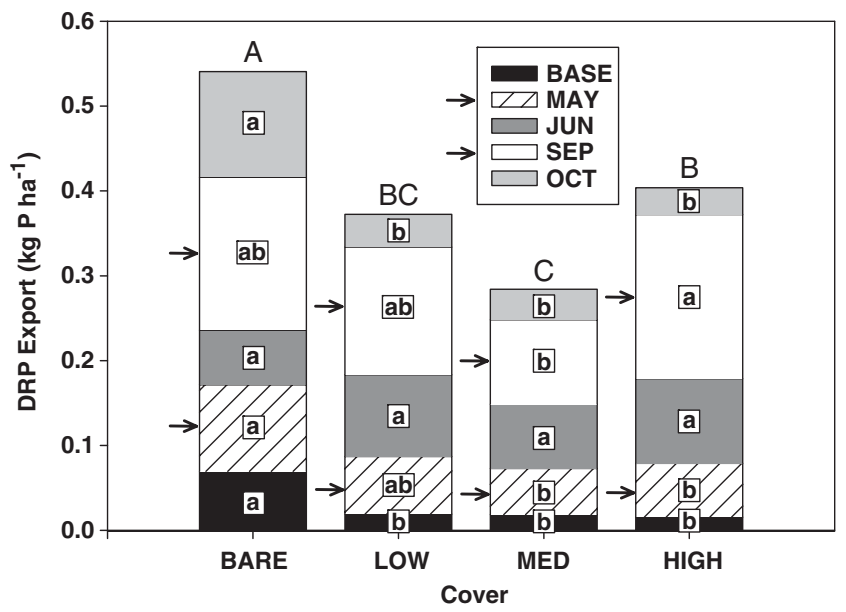

Fig. 3. Mean cumulative dissolved reactive phosphorus (DRP) export during $30 \mathrm{~min}$ of runoff as affected by cover, averaged across sites (means within the same rain event indicated by the same letter are not significantly different; capital letters indicate differences among the means of all rain events, $P>0.05$ ). The arrow pointing right indicates application of cattle feces and urine. medium cover than at high cover, which was the only rain event at which medium and high cover differed. However, neither high nor medium cover differed from bare ground or low cover for this rain event.

The trend in DRP export across levels of cover is more pronounced when all rain events are combined (Fig. 3). Mean DRP export was greater from bare ground than from low, medium, or high cover. However, DRP export from medium cover was $30 \%$ less than from high cover. The lower export from medium cover compared to high cover is surprising, and could be due to a number of factors. Among these is reduced P loss from vegetation on the plots at medium cover or increased $\mathrm{P}$ binding to clay minerals due to greater exposed soil surface at medium cover ( $70 \%$ basal cover) compared to high cover. There are few data that report DRP export as compared to percentage of ground cover, though Edwards et al. (2000b) reported a trend of increased DRP concentration in runoff with simulated "overgrazed" treatments clipped to $2.5 \mathrm{~cm}$ compared to higher clipping heights or no clipping.

Export of DRP was also plotted against actual canopy cover measurements (excluding the bare ground treatment) to determine if any differences were evident that were not apparent when evaluating DRP export in relation to treatment cover levels. The analysis indicated that canopy cover was not significantly related to export of DRP.

Generally, DRP export was much lower than that seen in other studies in the Southeast, which may in part be a function of moderate Mehlich-3 soil $\mathrm{P}$ values and a relatively low rate of $\mathrm{P}$ application in the cattle feces and urine. Many other studies of runoff from grasslands in the Southeast involve application of poultry litter, at a higher $\mathrm{P}$ application rate, because it is a source for improved pasture productivity. In Georgia, Kuykendall et al. (1999) reported annual losses of 8.6 to $11.5 \mathrm{~kg} \mathrm{P}$ $\mathrm{ha}^{-1} \mathrm{yr}^{-1}$ from pasture with applied poultry litter, compared to the mean annual DRP export from this study of $0.4 \mathrm{~kg} \mathrm{P} \mathrm{ha}^{-1} \mathrm{yr}^{-1}$.

\section{Total Kjeldahl Phosphorus}

Analysis of TKP export in this study indicated that cover had a substantial impact $(P<0.001)$ and rain event had a lesser impact $(P<0.01)$, while site alone did not significantly affect TKP export during $30 \mathrm{~min}$ of runoff (Table 3). A strong interaction was also noted between cover and rain event $(P<0.001)$.

At each rain event with the exception of June, bare ground plots had greater mean TKP export than plots at low, medium, or high cover, which were similar (Fig. 4). In June, there was no difference between mean TKP export at any level of cover. This was likely related to the low runoff volume from bare ground plots during the June rain event (Fig. 1) and lower associated TSS export from those same plots. Soluble P, sedimentbound $\mathrm{P}$, and $\mathrm{P}$ in eroded organic matter are constituents of TKP export (Daniel et al., 1994). Thus, TKP at the June event was largely DRP, as is usual when TSS is low (Edwards et al., 2000a). Consistent with TKP export 


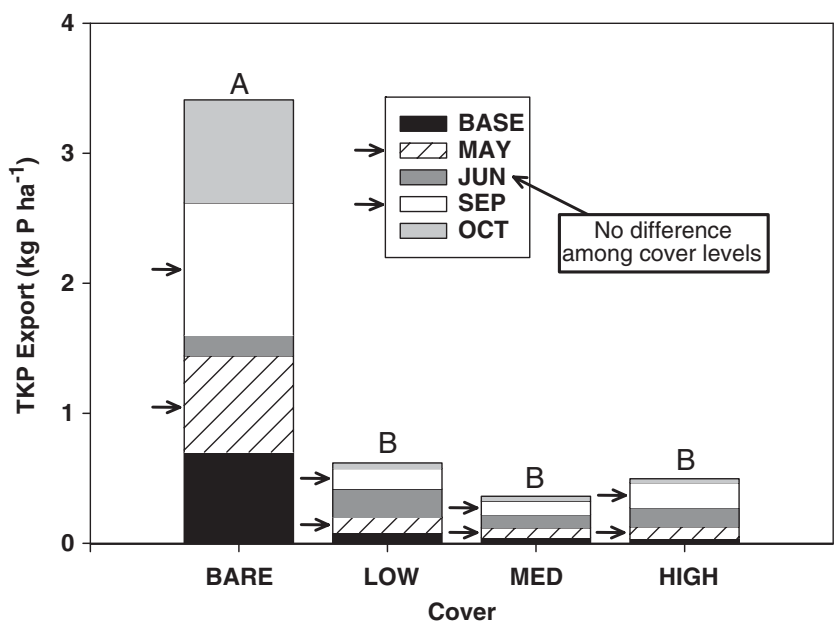

Fig. 4. Mean cumulative total Kjeldahl phosphorus (TKP) export during $30 \mathrm{~min}$ of runoff as affected by cover, averaged across sites (bars indicated by the same letter are not significantly different, $P>$ 0.05). The arrow pointing right indicates application of cattle feces and urine.

during individual rain events, the bare ground treatment produced the greatest TKP export when all rain events were combined.

It is also interesting to note DRP as a fraction of TKP (Table 6). While there was no difference among low, medium, and high cover levels for any rain event, in general a lower proportion of TKP was present as DRP from the bare ground treatment compared to the three levels of vegetative cover, consistent with a greater export of TSS from bare ground plots. The trend for an increased proportion of TKP as DRP during September and October rain events was likewise consistent with reduced TSS export during fall rain events. For rain events May through October, the mean proportion of DRP accounting for TKP generally ranged from 49 to $87 \%$ on vegetated plots, which is similar to the $68 \%$ reported by Kuykendall et al. (1999) from pastures with applied poultry litter, but less than the $85 \%$ reported by Edwards et al. (2000b) from applied cattle feces and urine.

In New Zealand, Gillingham and Thorrold (2000) reviewed several sources and reported that TP losses from pasture ranged from 0.1 to $1.67 \mathrm{~kg} \mathrm{P} \mathrm{ha}^{-1} \mathrm{yr}^{-1}$, which was similar to the mean annual export of $2.34 \mathrm{~kg} \mathrm{P}$ $\mathrm{ha}^{-1} \mathrm{yr}^{-1}$ observed in this study. However, under typical precipitation patterns actual annual export would likely be much less than in this study, as the five heavy simulated rain events represented a worse-case scenario.

Table 6. Percentage of total Kjeldahl phosphorus (TKP) as dissolved reactive $P$ (DRP).

\begin{tabular}{|c|c|c|c|c|c|}
\hline \multirow[b]{2}{*}{ Cover } & \multicolumn{5}{|c|}{ Rain event } \\
\hline & Base & May & June & Sept. & Oct. \\
\hline & \multicolumn{5}{|c|}{ TKP as DRP, $\%$} \\
\hline Bare & $14 \mathbf{a} \dagger$ & $16 \mathbf{a}$ & $40 \mathrm{a}$ & $22 a$ & 20a \\
\hline Low & $38 \mathrm{~b}$ & $56 b$ & $61 a$ & $70 \mathrm{~b}$ & $78 b$ \\
\hline Medium & 43b & $59 b$ & $55 \mathbf{a}$ & 71b & $71 b$ \\
\hline High & $35 \mathbf{b}$ & $49 \mathrm{~b}$ & $61 a$ & $87 \mathrm{~b}$ & $60 \mathrm{~b}$ \\
\hline
\end{tabular}

$\dagger$ Means in the same column followed by the same letter are not significantly different $(P>0.05)$.
There are also some limitations of extrapolating export from small plot experiments to the field scale, though processes controlling $\mathrm{P}$ transport in runoff are likely similar (Sharpley and Kleinman, 2003).

\section{CONCLUSIONS}

Ground cover is an important variable affecting runoff volume and associated TSS, DRP, and TKP export from pastured riparian areas. Management for cover maintenance and elimination of livestock lounging areas would likely minimize sediment and $\mathrm{P}$ export. Results from this study where beef steer feces and urine were applied simulating a stocking rate of about 4 cows ha ${ }^{-1}$ $\mathrm{yr}^{-1}$ suggest that full ground cover is not necessary to control sediment and $\mathrm{P}$ export from riparian pasture, but that forages in riparian areas could be used as part of a rotational grazing system where canopy cover of 70 to $80 \%$ is maintained at a stand height of $10 \mathrm{~cm}$. While lower cover than these levels may also be sufficient, such levels were not examined in this study. Future work examining lower levels of cover than were established at the basal level in this study, perhaps as low as $10 \%$, with canopy and basal cover measured at each rain event would help to elucidate the relationships between cover and runoff. Large-scale grazing studies where cover is monitored would also be useful by providing more applied information to those managing livestock in and near riparian areas than would small-plot studies. A range of forage species and the stand height of those species could also be examined to determine the impact of forages with differing growth habits and seasonal distribution of growth on runoff constituents. Producers, action agencies like USDA-NRCS, and policymakers can use this information to evaluate site vulnerability to potentially costly losses of water, soil, and nutrients.

\section{ACKNOWLEDGMENTS}

Special thanks are extended to the following individuals for invaluable help with the completion of this project: Elizabeth Barton, Dr. Cavell Brownie, Sharon Freeman, Dr. Jerry Huntington, Justin Garrett, Heather Glennon, Ricardo Goulart, Everett Gupton, T.J. Holliday, Brenna Houchins, Aaron Maye, Nathan McClintock, Izzy Menius, Guillermo Ramirez, April Shaeffer, Lucie Smith, Dr. Bir Thapa, Pete Thompson, and Mike Weeks.

\section{REFERENCES}

Alderfer, R.B., and R.R. Robinson. 1947. Runoff from pastures in relation to grazing intensity and soil compaction. J. Am. Soc. Agron. 39:948-958.

Bates, G.E., C.S. Hoveland, M.A. McCann, J.H. Bouton, and N.S. Hill. 1996. Plant persistence and animal performance for continuously stocked alfalfa pastures at three forage allowances. J. Prod. Agric. 9:418-423.

Byers, H.L., M.L. Cabrera, M.K. Matthews, D.H. Franklin, J.G. Andrae, D.E. Radcliffe, M.A. McCann, H.A. Kuykendall, C.S. Hoveland, and V.H. Calvert, II. 2005. Phosphorus, Sediment, and Escherichia coli Loads in Unfenced Streams of Georgia Piedmont, USA. J. Environ. Qual. 34:2293-2300.

Carpenter, S.R., N.F. Caraco, D.L. Correll, R.W. Howarth, A.N. Sharpley, and V.H. Smith. 1998. Nonpoint pollution of surface waters with phosphorus and nitrogen. Ecol. Appl. 8:559-568. 
Clary, W.P. 1995. Vegetation and soil responses to grazing simulation on riparian meadows. J. Range Manage. 48:18-25.

Cooper, C.M. 1993. Biological effects of agriculturally derived surface water pollutants on aquatic systems: A review. J. Environ. Qual. 22:402-408.

Costin, A.B. 1980. Runoff and soil losses from an improved pasture at Ginninderra, Southern Tablelands, New South Wales. Aust. J. Agric. Res. 31:533-546.

Cunniff, P. (ed.) 1995. Official methods of analysis of AOAC international, Vol. I. AOAC Int., Gaithersburg, MD.

Dadkhah, M., and G.F. Gifford. 1980. Influence of vegetation, rock cover, and trampling on infiltration rates and sediment production. Water Resour. Bull. 16:979-986.

Daniel, T.C., A.N. Sharpley, D.R. Edwards, R. Wedepohl, and J.L. Lemunyon. 1994. Minimizing surface water eutrophication from agriculture by phosphorus management. J. Soil Water Conserv. 49:30-38.

Edwards, D.R., T.K. Hutchens, R.W. Rhodes, B.T. Larson, and L. Dunn. 2000b. Quality of runoff from plots with simulated grazing. J. Am. Water Resour. Assoc. 36:1063-1073.

Edwards, D.R., T.T. Lim, and B.T. Larson. 2000a. Runoff nutrient and fecal coliform content from cattle manure application to fescue plots. J. Am. Water Resour. Assoc. 36:711-724.

Franklin, D.H., M.L. Cabrera, and V.H. Calvert. 2006. Fertilizer source and soil aeration effects on runoff volume and quality. Soil Sci. Soc. Am. J. 70:84-89.

Gillingham, A.G., and B.S. Thorrold. 2000. A review of New Zealand research measuring phosphorus in runoff from pasture. J. Environ. Qual. 29:88-96.

Hershfield, D.M. 1961. Rainfall frequency atlas of the United States for durations from 30 minutes to 24 hours and return periods from 1 to 100 years. Weather Bureau Tech. Paper 40. U.S. Weather Bureau, Washington, DC.

Jin, C.X., and M.J.M. Romkens. 2001. Experimental studies of factors in determining sediment trapping in vegetative filter strips. Trans. ASAE 44:277-288.

Kleinman, P.J.A., A.N. Sharpley, B.G. Moyer, and G.F. Elwinger. 2002a. Effect of mineral and manure phosphorus sources on runoff phosphorus. J. Environ. Qual. 31:2026-2033.

Kleinman, P.J.A., A.N. Sharpley, A.M. Wolf, D.B. Beegle, and P.A. Moore, Jr. 2002b. Measuring water-extractable phosphorus in manure as an indicator of phosphorus in runoff. Soil Sci. Soc. Am. J. 66:2009-2015.

Kohn, R.A., M.M. Dinneen, and E. Russek-Cohen. 2005. Using blood urea nitrogen to predict nitrogen excretion and efficiency of nitrogen utilization in cattle, sheep, goats, horses, pigs, and rats. J. Anim. Sci. 83:879-889.

Kuykendall, H.A., M.L. Cabrera, and C.S. Hoveland. 1999. Stocking method effects on nutrient runoff from pastures fertilized with broiler litter. J. Environ. Qual. 28:1886-1890.
Laflen, J.M., M. Amemiya, and E.A. Hintz. 1981. Measuring crop residue cover. J. Soil Water Conserv. 6:341-343.

Lang, R.D. 1979. The effect of ground cover on surface runoff from experimental plots. J. Soil Conserv. Serv. N. S. W. 35:108-114.

McGinty, W.A., F.E. Smeins, and L.B. Merrill. 1979. Influence of soil, vegetation, and grazing management on infiltration rate and sediment production of Edwards Plateau rangeland. J. Range Manage. 32:33-37.

McKenzie, F.R. 1997. Influence of grazing frequency and intensity on the density and persistence of Lolium perenne tillers under subtropical conditions. Trop. Grassl. 31:219-226.

Mehlich, A. 1984. Mehlich 3 soil test extractant: A modification of the Mehlich 2 extractant. Commun. Soil Sci. Plant Anal. 15:1409-1416.

Murphy, J., and J.P. Riley. 1962. A modified single solution method for the determination of phosphate in natural waters. Anal. Chim. Acta 27:31-36.

Mwendera, E.J., and M.A.M. Saleem. 1997. Infiltration rates, surface runoff, and soil loss as influenced by grazing pressure in the Ethiopian highlands. Soil Use Manage. 13:29-35.

Pote, D.H., T.C. Daniel, A.N. Sharpley, P.A. Moore, Jr., D.R. Edwards, and D.J. Nichols. 1996. Relating extractable soil phosphorus to phosphorus losses in runoff. Soil Sci. Soc. Am. J. 60:855-859.

SAS Institute. 1994. SAS/STAT user's guide. Version 8. 2nd ed. SAS Inst., Cary, NC.

Sauer, T.J., T.C. Daniel, P.A. Moore, Jr., K.P. Coffey, D.J. Nichols, and C.P. West. 1999. Poultry litter and grazing animal waste effects on runoff water quality. J. Environ. Qual. 28:860-865.

Schepers, J.S., and D.D. Francis. 1982. Chemical water quality of runoff from grazing land in Nebraska: I. Influence of grazing livestock. J. Environ. Qual. 11:351-354.

Self-Davis, M.L., P.A. Moore, Jr., T.C. Daniel, D.J. Nichols, T.J. Sauer, C.P. West, G.E. Aiken, and D.R. Edwards. 2003. Forage species and canopy cover effects on runoff from small plots. J. Soil Water Conserv. 58:349-359.

Sharpley, A.N., and P. Kleinman. 2003. Effect of rainfall simulator and plot scale on overland flow and phosphorus transport. J. Environ. Qual. 32:2172-2179.

USDA. 2002. Census of agriculture. National Agric. Statistics Serv., Washington, DC

USEPA. 1979. Methods for chemical analysis of water and wastes Environmental monitoring and support laboratory. Rep. 600/4 79-020. USEPA, Cincinnati, OH.

USEPA. 1992. Methods for the determination of metals in environmental samples. Environmental monitoring systems laboratory. Rep. 600/R-94-111. USEPA, Cincinnati, OH.

White, R.K., L.B. Owens, R.W. VanKeuren, and W.M. Edwards. 1980. Nonpoint surface runoff from cattle pasture-Hydrology and nutrients. p. 293-313. In Livestock waste: A renewable resource. Proc. of the 4th Int. Symp. on Livestock Wastes, Amarillo, TX. 1013 July 1980. Texas Tech Univ. Press, Lubbock. 